\title{
Innovative drug treatment in depression Hans-Jórgen Mфller
}

\author{
Address: Psychiatric University Department Munich, Germany \\ from International Society on Brain and Behaviour: 3rd International Congress on Brain and Behaviour \\ Thessaloniki, Greece. 28 November - 2 December 2007 \\ Published: 17 April 2008 \\ Annals of General Psychiatry 2008, 7(SuppI I):S7I doi:I0.II86/I744-859X-7-SI-S7I
}

This abstract is available from: http://www.annals-general-psychiatry.com/content/7/SI/S7I

(C) 2008 M $\phi$ ller; licensee BioMed Central Ltd.

Although there is no doubt about its efficiency, pharmacotherapy of depression still faces several problems that have to be focused upon and hopefully solved. Besides the problem of drug-resistant depression, over the last decade the view has become increasingly widespread that achieving remission is just as important as only response. Follow-up data show very clearly that non-remitters have a much higher risk of relapse/recurrence or even chronicity than remitters. The problems of under-diagnosis and under-treatment of depression also need to be addressed.

As for the near future, there is great hope that new mechanisms of action can overcome the limitations of the traditional and current antidepressant medications. Unfortunately, some of the recent developments that raised the most interest either turned out to be less effective than hoped, such as the substance P antagonists, or did not yet lead to a drug likely to be marketed in the near future, such as CRF antagonists, for example. On the other hand the first melatonergic antidepressant, agomelatine, is a successful new development. Agomelatine is a melatonergic MT1 and MT2 receptor agonist with 5-HT2C receptor antagonistic properties, and has shown antidepressant efficacy and favourable tolerability in several clinical trials on patients with major depression.

Drug development is evolving fast and is aided by improved brain imaging techniques, better animal models, and an increased knowledge of genetic markers. Hopefully this will result in a change in the pharmacotherapy of depression and psychiatric diseases in general, not on short term, but certainly in the next 50 years. 